\title{
Absence of symbolic and sustainable aspects in recommendations for healthy eating: a qualitative analysis of food-based dietary guidelines
}

\section{Ausência de aspectos simbólicos e sustentáveis \\ nas recomendações para alimentação \\ saudável: uma análise qualitativa \\ dos guias alimentares}

\author{
Rafaela Karen FABRI ${ }^{1}$ (D) 0000-0001-5282-9951 \\ Suellen Secchi MARTINELLI ${ }^{2}$ 0000-0001-9263-0867 \\ Maria Angela PERITO3 ${ }^{3}$ (DD) 0000-0002-3115-1288 \\ Andrea FANTINI ${ }^{3}$ ID 0000-0002-1149-008X \\ Suzi Barletto CAVALLI ID 0000-0002-2835-9424
}

A B S T R A C T

\section{Objective}

Was analyzed the contents of the main messages of food-based dietary guidelines to promote healthy eating, identifying nutritional, symbolic, and sustainable recommendations.

\footnotetext{
1 Universidade Federal de Santa Catarina, Centro de Ciências da Saúde, Programa de Pós-Graduação em Nutrição. Campus Universitário, R. Delfino Conti, s/n., Bairro Trindade, 88040-900, Florianópolis, SC, Brasil. Correspondence to: RK FABRI. E-mail: <rafaela.kfabri@gmail.com>.

2 Universidade Federal de Santa Catarina, Centro de Ciências da Saúde, Departamento de Nutrição. Florianópolis, SC, Brasil.

3 Universidade de Teramo, Faculdade de Ciências Biológicas e Tecnologia Agroalimentar e Ambiental, Laboratório de Economia e Marketing Agroalimentar. Teramo, TE, Itália.

Article elaborated from the thesis by RF FABRI, entitled "Aspectos simbólicos e sustentáveis na percepção sobre alimentação saudável de indivíduos adultos de Florianópolis e em guias alimentares". Universidade Federal de Santa Catarina; 2020.
}

How to cite this article

Fabri RK, Martinelli SS, Perito MA, Fantini A, Cavali SB. Absence of symbolic and sustainable aspects in recommendations for healthy eating: a qualitative analysis of food-based dietary guidelines. Rev Nutr. 2021;34:e200120. https://doi.org/10.1590/1678$9865202134 \mathrm{e} 200120$ 


\section{Methods}

Food-based dietary guidelines from 90 different countries were analyzed. These guidelines were selected from the United Nations Food and Agriculture Organization database. For data extraction, all messages were exported to the Nvivo software and, after repeated readings, were grouped into predefined categories and corresponding dimensions based on the literature. The categories were created according to the mixed model, that is, they were created before data analysis was performed, but modified if necessary.

\section{Results}

Was identified 1,982 messages grouped into the following dimensions: nutritional ( $n=73.9 \%)$; sustainable (3.2\%); symbolic (3.3\%), and others (19.7\%). All food-based dietary guidelines addressed nutritional aspects, and the most frequent recommendation was regarding the consumption of fats, followed by the consumption of salt and vegetables and fruits, cited by at least 75 food-based dietary guidelines. Less than half $(n=40)$ of the food-based dietary guidelines addressed sustainable or symbolic aspects of food and 13 of the food-based dietary guidelines addressed both aspects. However, these messages represented only $6.5 \%$ of the total messages in the documents.

\section{Conclusion}

The recommendations for healthy eating in the food-based dietary guidelines are incipient in terms of sustainable and symbolic issues. Recommendations for adopting healthy diets need to consider the completeness of the food and its various combinations, dietary patterns, and the factors associated with their consumption, as well as the individual's relations with food, environment, and society.

Keywords: Culture. Diet, food, and nutrition. Food guide. Food habits. Sustainable development.

\section{R E S U M O}

\section{Objetivo}

Analisar o conteúdo das principais mensagens de guias alimentares para promoção de alimentação saudável, identificando recomendações nutricionais, simbólicas e sustentáveis.

\section{Métodos}

Foram analisadas as mensagens de 90 guias alimentares selecionados a partir do banco de dados da Organização das Nações Unidas para Agricultura e Alimentação. Para a extração dos dados, todas as mensagens foram exportadas para o software Nvivo e categorizadas em categorias pré-definidas em revisão narrativa, conforme as dimensões correspondentes e outras categorias emergentes.

\section{Resultados}

Categorizou-se um total de 1.982 mensagens, agrupadas nas dimensões: nutricional ( $n=73,9 \%)$; sustentável (3,2\%); simbólica (3,3\%) e outras (19,7\%). Todos os guias abordavam aspectos nutricionais, sendo que a recomendação mais frequente foi em relação ao consumo de gordura, seguida do consumo de sal e vegetais e frutas, citadas por pelo menos 75 guias. Menos da metade dos guias $(n=40)$ abordaram aspectos sustentáveis ou simbólicos da alimentação e 13 abordaram ambos; contudo, essas mensagens representaram 6,5\% do total presente nos documentos.

\section{Conclusão}

As recomendações para alimentação saudável presentes nos guias alimentares são incipientes no que se refere a questões sustentáveis e simbólicas. Recomendações para a adoção de dietas saudáveis precisam considerar a integralidade do alimento, as diversas combinações, os padrões alimentares e os fatores associados ao seu consumo, bem como as relações do indivíduo com o alimento, com o ambiente e com a sociedade.

Palavras-chave: Cultura. Alimentos, dieta e nutrição. Guias alimentares. Hábitos alimentares. Desenvolvimento sustentável.

\section{INTRODUCTION}

The food system has undergone several changes in recent decades, from production to consumption. Negative impacts on the environment and society are beginning to emerge as a result of modern agricultural practices such as intensive land use, monoculture, irrigation, application of inorganic fertilizer, chemical 
pest control, and genetic manipulation of plants [1]. The commercialization of food is characterized by an increase in the distances between production and consumption, which causes loss of cultural identity, uniformity of products, and ignorance of the origin and production methods [2,3]. Changes in the patterns of production and consumption of food [3-6] worldwide have resulted in a standardization of contemporary eating practices $[3,5]$. There is a high consumption of processed foods with high levels of sugars, fats (mainly saturated and trans), and sodium $[3,5,7]$. As well as foods with large amounts of pesticide residues and genetically modified organisms [4,8-10].

Food choices have an important interaction with agricultural, environmental, and health systems, therefore, individual changes in the diet can influence the demand for certain foods and reduce pressure on the global food system [11]. For this, it is necessary provide the population with information and influence their behavior of choice [12]. The disclosure of nutritional recommendations is essential for the control of overweight and obesity in the world [13]. However, an increasing number of countries have recognized that food policies must integrate the objective of improving the health and also the well-being of people and the environment [14]. Strategies to promote healthy eating are urgent and must involve all sectors of society and the food system [15].

However, the vision of food as a vehicle for nutrients and substances to reduce the risk of diseases has dominated nutrition science and dietary recommendations [16-18]. The recommendations centered on the consumption of nutrients and their effects on the body and energy balance is a reductionist view of food, leading to a distancing of the population in relation to food, origin, mode of production, culture, and other aspects that shape dietary habits $[19,20]$. Furthermore, it has favored simplified interpretations regarding the exclusive role of nutrients in health and the classification of foods into good and bad, a sometimes mistaken notion $[20,21]$. The health and nutrient relationship consists of only one of the factors that influence food choices, so a reductionist approach seems to be questionable and insufficient [19].

In view of this scenario, the need for recommendations that address the issue of current production and consumption is evident, encompassing the relationship between diet, health, environment, and society $[8,22,23]$. Feeding is a complex phenomenon, not having the sole purpose of providing nutrients [3]. Incorporating sustainability issues into the recommendations for healthy eating has been identified as a key to nutrition policies $[8,22]$. Sustainability has different dimensions, with the environmental, social, and economic dimensions being known as the sustainability tripod [24].

According to the Food and Agriculture Organization of the United Nations (FAO), it is necessary to encourage diets that value foods that are part of tradition and culture; agriculture and traditional practices and local varieties, in order to help preserve the sovereignty and tradition of production, involving culturally acceptable food [4].

In this context, Food-Based Dietary Guidelines (FBDG) are official government instruments developed by an interdisciplinary team of specialists, containing guidelines to assist populations in their healthy food choices. To this end, they must be prepared according to the reality and needs in terms of the country's food and updated scientific evidence $[25,26]$. They serve as a reference for the action of health professionals, public health actions, and direct communication with the population, so that the guidelines are consistent with the current concerns regarding food, health, and the environment $[26,27]$. Thus, they can be considered strategic instruments for education and promotion of healthy eating. FBDG are tools that are useful in the guidance regarding a wide range of foods and nutrition, health, agriculture and nutrition education policies and programs; representing a unique opportunity to positively impact diets and the food system, from production to consumption [25]. FAO, in turn, assists countries in the development, review and implementation of dietary guidelines, in addition to conducting periodic reviews of the countries' implementation of these guidelines [28]. 
In an analysis carried out by FAO, only four FBDG stood out for presenting guidelines for healthy eating that included sustainability in their aspects, these being Germany, Brazil, Sweden, and Qatar [29]. A review of 34 European FBDG identified that the basic messages for healthy eating were about: consuming adequate amounts of grains, legumes, and fruits with a moderate intake of fats, sugars, meats, caloric drinks, and salt [30]. A review of 90 FBDG identified similar nutritional guidelines [31].

Thus, it is observed that other aspects still do not seem to be well incorporated in the dietary recommendations [22]. The importance of nutritional content is recognized for the assessment and promotion of healthy eating practices, especially in view of the history of increased Chronic Noncommunicable Diseases (NCD) [32]. However, authors refer that this cannot be the only approach to classify practices as healthy or not, as they seem not to be sufficient $[8,22,32]$. Therefore, the objective of this study was to identify the recommendations regarding the nutritional, symbolic, and sustainable dimensions provided in FBDG for healthy eating directed to the population.

\section{METHODS}

The study analyzed the contents of the main messages of FBDG from different countries. The dietary guidelines contained in the FBDG for healthy adult individuals were included in the analysis. Therefore, the guidelines for children or population groups with special nutritional needs, such as pregnant women, lactating women and the elderly, or guidelines directed to the population with specific diseases, were not analyzed.

The FBDG were selected from the database made available by FAO [33]. These are made available in full along with their graphic representations (when available), in their native language versions. In addition, FAO provides the main guidelines present in these FBDG in the English language.

Thus, for this study, the main guidelines provided by FAO and not all the contents of these FBDG were analyzed and called the main messages, thus allowing the analysis of a greater number of documents by standardizing the language. The main messages were generally composed of short phrases, such as: "Consume more cereals, vegetables, tubers, and fruits" ; or "Vegetables and fruits - eat five servings a day".

Data collection was carried out between September and October 2018. Data were collected from FBDG of 90 countries. The information for each guideline was individually accessed and data were extracted according to: country of origin, geographical division proposed by FAO, year of publication, and dietary guidelines/ messages. It should be noted that countries sent FAO their FBDG data after an invitation from the Organization itself, which does not mean that other countries (not analyzed) do not have their official guidelines.

In order to support the analytical procedure of messages from the FBDG, a narrative review study was previously carried out. Narrative review studies are publications for the purpose of describing and discussing the state of the art of a given subject [34]. This narrative review was carried out by one of the authors between August 2016 and November 2017, being updated in 2018, without limitation of date, country of study, or area of knowledge. Original articles, review articles, and gray literature (institutional and government documents and reports) in English, Spanish, and Portuguese were included in the study. The review sought to help define the aspects that would be considered as part of the dimensions of analysis, so it sought to answer the following question: What are the nutritional, symbolic, and sustainable aspects for the promotion of a healthy diet?

The research was carried out on Scopus, PsycInfo, Assia, and SciELO databases, in addition to consultations of theses and dissertations in the Coordination of Superior Level Staff Improvement Journals database, webpages such as Researchgate and Google Scholar. For the search in the English language, 
the research queries "Medical Subject Heading (MeSH)" and "Descritores em Ciências da Saúde, Health Sciencs Descriptors (DeCS)" were initially used; from the terms identified in the articles, keywords were defined to perform new research. The groups of terms used were about healthy eating ("health* food", "health" eat*", "health* diet" ", "health* feed" , "health" meal", "healthy eating habits", "health* choice" , "health" food" consumption), associated or not with sustainability terms (Sustaina* diet" ", "sustaina* food", "sustaina* meal", "sustaina* dishe*", "sustaina* feed ", "sustaina* choice", "sustaina* eat" ", "sustaina* practice", "Eco-friendly practices", "Green practices", "Environmentally Friendly Practices") and symbolic aspects ("Regional food", "regional dish", "tradition" food", "tradition* feed", "tradition* gastrono", "cultur ${ }^{*}$ food", "cultur ${ }^{*}$ feed", "cultur" diet" ", "food cultur" heritage", "Gastrono* Heritage", "food heritage", " typic food, typic dish", "typic* gastrono*"). Additionally, the words related to healthy eating were associated with terms related to the words related to "recommendation" (recommendation* "OR" politic "OR" guide*").

From the narrative review of the literature, it was possible to identify aspects related to the nutritional, symbolic, and sustainable dimensions. The predefined categories of each group, as well as the references used to support the classification can be seen in Chart 1 .

Chart 1 - Predefined literature and reference categories that supported the categorization of recommendations in the Nutritional, Symbolic, and Sustainable dimensions. Florianópolis, Brazil, 2020.

\begin{tabular}{|c|c|}
\hline Predefined categories & References \\
\hline \multicolumn{2}{|l|}{ Dimension 1 - Essentially nutritional recommendations } \\
\hline Nutrient content of foods; food groups (meats, fruits and vegetables, cereals, among others) & {$[7,35-38]$} \\
\hline Energy content; amount of calories & {$[7,35-37]$} \\
\hline Salt consumption & {$[7,37]$} \\
\hline Sugar consumption & {$[37,39]$} \\
\hline Consumption of oils and fats & {$[36,37]$} \\
\hline Consumption of food additives & {$[40,41]$} \\
\hline Consumption of processed foods & {$[36,37]$} \\
\hline Consumption of whole foods & {$[7,36,37]$} \\
\hline \multicolumn{2}{|l|}{ Dimension 2 - Essentially symbolic recommendations } \\
\hline Taste & {$[3,42]$} \\
\hline Presentation, color, and smell of foods & {$[3,42]$} \\
\hline $\begin{array}{l}\text { Valuing the cultural context of the individual or group; preservation of food culture and identity; consumption of } \\
\text { typical and traditional foods }\end{array}$ & {$[3,43-46]$} \\
\hline Valuing the knowledge and beliefs of the individual or group & {$[3,43,46]$} \\
\hline Eating as a time of social integration and friendship & {$[43,47]$} \\
\hline Take time to prepare and eat meals. Slow eating & {$[43,47]$} \\
\hline Eating with pleasure & {$[43,47]$} \\
\hline \multicolumn{2}{|l|}{ Dimension 3 - Essentially sustainable recommendations } \\
\hline Respect for seasonality & [37] \\
\hline Valuing biodiverse food & {$[4,36,48]$} \\
\hline Consumption of wild and unconventional plants & {$[49,50]$} \\
\hline Organic food consumption and enhancement of the agroecological production system & [51-53] \\
\hline Consumption of non-genetically modified food & {$[10,54,55]$} \\
\hline Food waste & {$[23,36,56,57]$} \\
\hline Consumption of local food and short marketing chains & {$[48,51,57,58]$} \\
\hline Food consumption by family farmers and small producers & {$[19,58]$} \\
\hline Food consumption from home and community gardens & [19] \\
\hline Consumption of fair-trade foods from a supportive economy & {$[56,59]$} \\
\hline Sustainable animal production/animal well-being & [23] \\
\hline Vegetable-based food & {$[36,48]$} \\
\hline
\end{tabular}


From the results of the narrative review, it was possible to categorize the recommendations present in the analyzed FBDG and divide them into the dimensions of interest. Considering the themes related to the study question, the results of the review were divided into three groups of recommendations for healthy eating: Dimension 1: Essentially nutritional recommendations. Dimension 2: Essentially symbolic recommendations; Dimension 3: Essentially sustainable recommendations. It is important to highlight that, despite the categorization of the message in the different dimensions (nutritional, symbolic, and sustainable) of a healthy diet, they articulate, overlap, and complement each other.

However, the categories were defined in each of the dimensions based on the direction indicated in the literature on healthy eating. For that purpose, it was sought the interpretation of the complete message and the analysis of literature. Recommendations for the consumption of vegetables and fruits, for example, are related to nutritional and sustainable aspects. However, they were classified as essentially nutritional due to the encouragement of consumption as part of a healthy diet and for helping to improve the nutritional aspects of the population's food and health. In addition, the term "essentially" was used in the categories because, despite the recognition that the categories overlap, the information is not always clear in the messages.

By nutritional dimension, we understood those attributes related to meeting the nutritional and biological needs of the organism. In this dimension, aspects such as recommendations on nutrients, specific foods, food groups were considered; among others whose content was related to health, food composition, nutritional composition, or similar issues. For example, recommendations on food additives and food processing were included in the nutritional dimension, since in the literature review on promoting healthy eating, these aspects were predominantly linked to the consumption of nutritionally unfavorable foods.

In the symbolic dimension, aspects that associated food with the understanding of the meanings that food has for the individual according to the social and cultural context in which it is inserted were considered [3]. It should be noted that the review sought to identify categories in each dimension, however, the pre-analysis categories were developed from a mixed model, that is, they were created a priori and could be modified, regrouped, or renamed from the content analysis, as well as emerging from the messages of the guidelines.

The sustainable dimension focuses on the role of food and food choices for environmental, social, and economical sustainability throughout the food system. Sustainable aspects were considered, such as the preservation of biodiversity, sustainable animal and vegetable production methods, short marketing chains, fair trade, among others [4,60-62].

The unit of analysis of the FBDG consisted of words and phrases present in the main messages, whose content was analyzed qualitatively through content analysis. The analysis consisted of highlighting segments of messages that reflected different ideas to identify these messages in comprehensive categories related to the predefined dimensions and categories of healthy eating [63]. Thus, a guideline could contain one or more units of analysis, classified into one or more categories, based on the research objectives, the literature review and the authors' experience with the theme, considering the promotion of healthy eating associated with nutritional, symbolic, and sustainable aspects. Therefore, the recommendation "Consume vegetables and fruits, preferably seasonal ones" was classified as part of the nutritional and sustainable dimension; the recommendation "Consume vegetables and fruits" was classified only in the nutritional dimension. These messages were imported and analyzed using the Nvivo 11.0 ${ }^{\circledR}$ software [64]. This codification process was carried out twice by one of the authors in an interval of 3 months and discussed with the other authors until a consensus was established.

Messages grouped into each category analyzed were counted. The data were analyzed in the form of simple frequency, distributed by groups and categories of analysis and by FBDG. All recommendations in the guidelines were analyzed and categorized in the interest groups created based on the literature. Those that 
did not address aspects related to any of the three groups were classified as Other recommendations. The data related to the analysis of the guidelines are presented as simple frequency, considering the number of messages present in each category, as well as the number of guidelines that contained those messages.

\section{R E S U L T S}

Ninety FBDG were analyzed and 1,982 recommendations for healthy eating targeted to the population were categorized. Most of the FBDG analyzed were from the European continent, representing 36.7\% ( $n=33)$, followed by Latin America and the Caribbean 31.1\%, $(n=28)$; and Asia 20\% ( $n=18)$. The year of publication varied, from 1986 to 2017, with four FBDG being published before the year 2000 and most being published (65.2\%) after 2009, 22.2\% after 2014 .

Table 1 shows the number of recommendations categorized in each dimension. The analysis of the messages indicated that $73.9 \%$ of them were recommendations classified as "Essentially nutritional" and all guidelines presented recommendations classified in this group. "Essentially symbolic" and "Essentially sustainable" recommendations represented 3.3\% $(n=65)$ and 3.2\% $(n=63)$ of recommendations for healthy eating and were present in 22 and 30 FBDG, respectively. A total of 88 FBDG presented messages classified as Other recommendations. These messages represented $19.7 \%(n=390)$ of the total recommendations.

Regarding recommendations containing symbolic and sustainable aspects, of the 90 FBDG, 13 (14.4\%) addressed both aspects and 40 (44.4\%) presented some message classified as sustainable or as symbolic. These represented $57 \%(n=16)$ of the total FBDG in America and the Caribbean, $45 \%(n=15)$ of European FBDG, 22\% ( $n=4)$ of Asian FBDG, 28.5\% ( $n=3)$ of African FBDG, and $50 \%(n=2)$ of Middle Eastern FBDG. Regarding the year of publication, it was observed that, among these 40 FBDG, $62.5 \%$ were published after 2009, 20\% after 2014.

The details of the number of messages present in each analysis category, as well as the number of FBDG regarding these recommendations can be seen in Table 2. Recommendations regarding fat consumption had the highest number of messages and were present in 79 of the 90 FBDG analyzed. Only one FBDG presented a message to reduce food waste and one FBDG encouraged the consumption of organic foods, these were from the Asian and American continents, respectively.

Table 1 - Number and percentage of food based dietary guidelines analyzed and the Nutritional, Symbolic, and Sustainable dimensions, categorized by year and place of publication. Florianópolis, Brazil, 2020.

\begin{tabular}{|c|c|c|c|c|c|c|c|c|}
\hline \multirow{3}{*}{$\begin{array}{l}\text { Characterization of the identified } \\
\text { guidelines and categories }\end{array}$} & \multirow{2}{*}{\multicolumn{2}{|c|}{ FGDB }} & \multicolumn{6}{|c|}{ FGDB } \\
\hline & & & \multicolumn{2}{|c|}{ Essentially nutritional } & \multicolumn{2}{|c|}{ Essentially symbolic } & \multicolumn{2}{|c|}{ Essentially sustainable } \\
\hline & $\mathrm{n}$ & $\%$ & $\mathrm{n}$ & $\%$ & $n$ & $\%$ & $\mathrm{n}$ & $\%$ \\
\hline \multicolumn{9}{|l|}{ Year of publication* } \\
\hline Before the year 2000 & 4 & 4.5 & 4 & 100.0 & 1 & 25.0 & 2 & 50.0 \\
\hline $2000-2008$ & 27 & 30.3 & 27 & 100.0 & 7 & 26.0 & 8 & 30.0 \\
\hline $2009-2013$ & 38 & 42.7 & 38 & 100.0 & 15 & 39.0 & 8 & 21.0 \\
\hline $2014-2017$ & 20 & 22.5 & 20 & 100.0 & 5 & 25.0 & 5 & 25.0 \\
\hline \multicolumn{9}{|l|}{ Place of publication } \\
\hline Europe & 33 & 36.7 & 33 & 100.0 & 8 & 24.0 & 10 & 30.0 \\
\hline Latin America and the Caribbean & 28 & 31.1 & 28 & 100.0 & 9 & 32.0 & 12 & 43.0 \\
\hline Asia & 18 & 20.0 & 18 & 100.0 & 2 & 11.0 & 4 & 22.0 \\
\hline Africa & 7 & 7.8 & 7 & 100.0 & 2 & 29.0 & 2 & 29.0 \\
\hline Middle East & 4 & 4.4 & 4 & 100.0 & 2 & 50.0 & 2 & 50.0 \\
\hline
\end{tabular}

Note: "The date of publication was not specified in one of the analyzed FBDG (Food-Based Dietary Guidelines). 
Table 2 - Number of messages and food based dietary guidelines (FBDGs) for all recommendations categorized as Nutritional, Symbolic, Sustainable, and Other recommendations. Florianópolis (Brazil), 2020.

\begin{tabular}{|c|c|c|}
\hline Dimensions and Category & Messages (n) & FBDGs $(n)$ \\
\hline \multicolumn{3}{|l|}{ Dimension 1 - Essentially nutritional recommendations } \\
\hline Fat consumption and use (Control of fat consumption in general, saturated fat, selection of foods with less fat) & 163 & 79 \\
\hline $\begin{array}{l}\text { Consumption and use of Salt (Control of the use of salt and foods with a large amount of salt/sodium and } \\
\text { selection of foods with less salt/sodium) }\end{array}$ & 162 & 79 \\
\hline $\begin{array}{l}\text { Consumption of Vegetables and Fruits (Encouraging the consumption of vegetables and fruits in quantity } \\
\text { and variety) }\end{array}$ & 156 & 75 \\
\hline $\begin{array}{l}\text { Meat Consumption (Encourage and control of meat consumption, lean meat consumption, control of fatty } \\
\text { meat consumption) }\end{array}$ & 128 & 57 \\
\hline $\begin{array}{l}\text { Sugar Consumption (Control of the consumption of sugar and high-sugar foods and beverages, and selection } \\
\text { of foods with less sugar) }\end{array}$ & 124 & 69 \\
\hline Milk Consumption (Encourage the consumption of dairy products in general and low-fat content) & 93 & 53 \\
\hline Varied food consumption (encouraging the consumption of different types of foods and food groups) & 92 & 67 \\
\hline Fish (Encouraging fish consumption) & 77 & 47 \\
\hline $\begin{array}{l}\text { General recommendations for a healthy and balanced diet (Healthy diet, balanced and/or moderate diet; } \\
\text { regular consumption and control of food consumption) }\end{array}$ & 59 & 34 \\
\hline Fibers (Encouraging the consumption of whole foods and foods rich in fiber) & 57 & 41 \\
\hline Oil (Control of oil consumption and vegetable oil consumption) & 57 & 42 \\
\hline Cereals and starches (Encourage the consumption) & 56 & 41 \\
\hline Other groups of food (Encouraging the consumption of nuts, seeds, among others) & 45 & 27 \\
\hline Legumes (Encourage the consumption) & 38 & 30 \\
\hline Eggs (Encourage the consumption) & 36 & 25 \\
\hline $\begin{array}{l}\text { Food processing (control over the consumption of processed, ultra-processed foods; preference for less } \\
\text { processed foods) }\end{array}$ & 32 & 15 \\
\hline Nutrients (Encourage the consumption of protein, carbohydrate, calcium, iron, among others) & 30 & 19 \\
\hline Meals (Hours, number, and type of meals) & 23 & 13 \\
\hline Calories (Control the amount of calories consumed) & 18 & 12 \\
\hline Food labeling (reading nutritional information) & 18 & 11 \\
\hline Total & 1,464 & 90 \\
\hline
\end{tabular}

Dimension 2 - Essentially symbolic recommendations

Appreciation of food culture, food, and traditional cuisine $\quad 24 \quad 11$

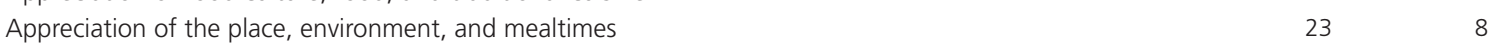

Enjoying the meal

\begin{tabular}{|c|c|c|}
\hline Total & 65 & 22 \\
\hline \multicolumn{3}{|l|}{ Dimension 3 - Essentially sustainable recommendations } \\
\hline Consumption of fresh and/or natural food & 24 & 17 \\
\hline Valuing local food & 14 & 11 \\
\hline Vegetable-based diet & 11 & 9 \\
\hline Respect for seasonality & 9 & 7 \\
\hline Valorization of organic foods & 2 & 1 \\
\hline Environmental protection & 2 & 2 \\
\hline Waste reduction & 1 & 1 \\
\hline Total recommendations & 63 & 30 \\
\hline \multicolumn{3}{|l|}{ Dimension 4 - Other recommendations } \\
\hline Physical activity & 74 & 62 \\
\hline Hygiene & 71 & 41 \\
\hline Water and other liquids & 66 & 55 \\
\hline Weight & 64 & 49 \\
\hline Alcoholic beverages & 48 & 42 \\
\hline Breastfeeding & 31 & 21 \\
\hline For different population groups & 11 & 6 \\
\hline Complementary diet & 9 & 8 \\
\hline Health care and disease prevention (not associated with food) & 9 & 6 \\
\hline Use of financial resources & 4 & 3 \\
\hline Smoking & 3 & 3 \\
\hline Total & 390 & 88 \\
\hline
\end{tabular}

Note: FBDG (Food-Based Dietary Guidelines). 


\section{DISCUSSION}

The aim of this study was to identify recommendations for healthy eating aimed at the population. All nutritional recommendations identified in the literature review were present in the FBDG, except for recommendations on the consumption of food additives. On the other hand, sustainable recommendations such as the consumption of foods that promote biodiversity, non-genetically modified food, from small producers, and from a fairer trade regime were not observed.

The results demonstrate the predominance of the nutritional perspective in strategies to promote healthy eating in FBDG around the world, in view of the large number of messages classified in the nutritional dimension in comparison with the other dimensions. In particular, it was observed that most FBDG made recommendations in relation to fat, salt, vegetables and fruits, sugar, and varied diets. Of the total of FBDG analyzed, 40 addressed symbolic and/or sustainable dimensions of food, that is, 50 FBDG did not bring any recommendation directly encompassing aspects that were classified as symbolic or as sustainable. In addition, if we consider the total number of messages analyzed, sustainable and symbolic messages represented only $6.3 \%$ of the total number of messages in the documents. The consumption of fresh and natural food was the sustainable recommendation present in a greater number of guidelines $(n=17)$, while the consumption of organic food as part of a healthy diet and the reduction of waste had the least frequency. Recommendations related to cultural aspects of the diet, such as appreciation of culture and meals, were also incipient.

The messages classified in the "Other recommendations" category represented almost 20\% of the total analyzed messages and were present in almost all the FBDG analyzed $(n=88)$. These messages were mainly related to guidelines for physical activity, adequate hygiene practices, weight control, and consumption of water and other liquids. Together, these messages represented $70 \%$ of the messages classified in this group.

The centrality of nutritional recommendations in FBDG has already been observed in other studies $[30,38]$. The large number of messages about healthy eating and diet, the contradictory discourses among researchers, health professionals and the media, the continuous development of Nutrition science and the different concepts and terminologies used, have made it difficult for the consumers to understand about healthy eating $[6,38,65]$. Healthy eating is not always understood and interpreted uniformly among consumers [65]. Furthermore, it can lead to a symbolic and/or nutritional dissonance between what is internalized by the individual and his real practices [3].

Although the discussion on the importance of promoting sustainable and symbolic aspects is not recent, few FBDG analyzed have included these dimensions in their recommendations [3,4]. Most FBDG published after 2014 did not provide any guidance in this regard. Latin America and the Caribbean stood out in relation to the other regions for presenting a greater number of guidelines (absolute number) that addressed both symbolic and sustainable issues. The lack of approach regarding the influence of socioeconomical, cultural and political factors on eating habits can influence the practical adherence to the recommendations in these FBDG [66]. Considering the challenges observed for a sustainable diet, political guidelines for changing food systems are still insufficient, despite the indication of an unsustainable global food system $[4,36]$.

The guidelines related to sustainability aspects were directed to the consumption of fresh and natural food, place of production, and seasonality. Although the consumption of vegetables and fruits is present in almost all the guidelines, seven highlighted the importance of seasonal foods and only one recommended the consumption of organic and agroecological foods. 
There is a disconnection between the recommendations with a nutritional approach (centered on nutrient, food, or food groups) and food production. For example, recommendations for the consumption of vegetables and fruits can stimulate the demand for fresh, natural, and organic foods. This, in turn, could encourage greater production of these foods. However, the guidelines did not present a direct and articulated connection between consumption and production in their messages. More than that, the messages of the FBDGs did not expose, in a clear and direct way, the impacts that the recommendation can have beyond health, in order to assist the population in the expanded understanding of healthy eating $[16,19,67]$.

The approach centered on nutritional issues can reflect what individuals have perceived as part of a healthy diet. Review studies on the perception of healthy eating have identified conceptions related mainly to the presence of fruits and legumes; natural and whole foods; restriction of fat, sugar, and salt; and a low-calorie diet $[38,68]$. The promotion of dietary modifications focusing only on nutritional aspects has a limited effect in reducing environmental impacts [68] and appears to be insufficient in preventing NCDs [16]. National food guidelines should use a more holistic approach to food, highlighting diet sustainability through recommendations that protect human health, animal well-being, and the environment [16].

It is believed that the consensus on the promotion of diets based on foods of vegetable origin and a greater consumption of vegetables and fruits, with a view to preventing diseases and promoting healthy eating, should imply the identification and support of sustainable production practices. The importance of promoting the purchase of foods from family-based farming (absent in food based dietary guidelines) is highlighted, which is considered important for the supply of vegetables and fruits, regional and socio-biodiverse foods, among other fresh foods, being primarily responsible for feeding populations [68-71].

The motivations for consumers to consider these aspects in their food choices are still not well understood [72]. Even more complex are the changes in food choices seeking to incorporate sustainable and symbolic aspects $[3,43,73]$. Different from globalized food, there is a greater interest from consumers in opposite movements, such as organic food [74]. Local foods, associated with a place of origin; traditional foods and part of the local culture, which may be raising awareness of symbolic and sustainable aspects as part of healthy eating [75].

Symbolic recommendations were related to the habits of preparing and eating meals, the place where meals are eaten, and the appreciation of traditional culture and foods. In this sense, some of the FBDGs analyzed stressed the importance of the pleasure of eating, sharing meals, and understanding and enjoying the moment of eating meals as a moment of socialization. These guidelines, despite presenting these messages in a subtle way, addressed the act of eating beyond the simple ingestion of foods and nutrients.

A study conducted by Oliveira and Santos [76] analyzed the two versions of the Brazilian food based dietary guidelines and found that both addressed the relationship between food and social and cultural dimensions. In the first version, there was a predominance of medical-nutritional discourse, while in the second one, the central discourse is related to fresh or minimally processed foods and culinary preparations. FAO has pointed out that the Brazilian FBDG deserves to be highlighted for addressing social and cultural food issues when making recommendations on the consumption of ultra-processed foods [29].

The act of eating is full of symbolism that directly or indirectly influences food choices and that need to be respected in order to have a healthy diet [3]. Traditional foods or preparations are part of the food culture, rescuing bonds and affective and taste memories. They involve preparation based on family recipes or that rescue this family memory [3]. Thus, guidelines on how to consume food 
part of your culture or family history could also encourage greater preparation of meals at home, a practice associated with improving the quality of food [77]. Still, the importance of valuing culture and food is part of tradition, of local ways of doing and knowing, is directly related to the valuation of local, fresh, natural products, biodiversity, produced by small producers, and reduction in the consumption of industrialized foods.

The promotion of healthy food choices must incorporate a joint and balanced approach of the different dimensions that involve food, which are: nutritional, symbolic, sustainable, hygienic-sanitary, sensory, political, and social $[3,78]$. For a food to be considered healthy it needs to be produced in an environmentally sustainable, socially fair, and economically viable food system, to ensure the population's food security as a whole and favor sustainable development [4].

When interpreting our results, it is important to consider that FAO presents the main messages from FBDG sent by each country to the organization, which does not mean that other places do not have recommendations. The analysis did not occur in the entirety of these FBDG and the results may not express the complexity of the discussions in the complete document. It was decided to analyze the main messages of the FBDG, as it provides a comprehensive view of the information on healthy eating directed to the world population. It is noteworthy that some messages coded as 'essentially nutritional' can impact the environment and society, as well as commensality and food culture and, therefore, could have been classified as sustainable or symbolic. However, we chose to categorize as sustainable or symbolic only those that showed this relationship to the reader. In this sense, this study demonstrated that sustainable and symbolic aspects must be clearly inserted in FBDG, encouraging healthy eating in all its dimensions.

\section{CONCLUSION}

The FBDG analyzed focus their recommendations on the nutritional quality of the food, not associating sustainable and symbolic aspects as part of a healthy diet. Sustainable and symbolic recommendations were incipient and addressed by the minority of FBDG. To advance in ensuring a diet considered healthy in all its dimensions, FBDG need to insert symbolic and sustainable aspects in their recommendations. Recommendations for adopting healthy diets should be centered on several dimensions that consider the completeness of the food and the various combinations, dietary patterns and factors associated with their consumption; as well as the individual's relations with food, environment, and society.

\section{ACKNOWLEDGMENTS}

We would like to thank the Coordenação de Aperfeiçoamento de Pessoal de Nível Superior (Capes, Coordination for the Improvement of Higher Education Personnel) for the scholarship granted, which enabled us to dedicate the time and energy required to carry out the research, in Brazil and abroad.

\section{CONTRIBUTORS}

RK FABRI was responsible for the conception and design of the study, data analysis and interpretation, and writing the article. SS MARTINELLI contributed to data interpretation and writing the article. MA PERITO supervised the steps developed in doctoral stay, assisting in the article review and adjustment. A FANTINI assisted in the article review and adjustment. SB CAVALLI was responsible for research coordination and article guidance and review. 


\section{REFERE N CES}

1. Frison EA; IPES-Food. From uniformity to diversity: a paradigm shift from industrial agriculture to diversified agroecological systems. Louvain-la-Neuve (Belgium): IPES; 2016.

2. Thomas K, Karl-Heinz E, Helmut H. Rapid growth in agricultural trade: effects on global area efficiency and the role of management. Environ Res Lett. 2014;9:034015. https://doi.org/10.1088/1748-9326/9/3/034015

3. Poulain JP. Sociologia da alimentação: os comedores e o espaço social alimentar. Florianópolis: EDUFSC; 2012.

4. Food and Agriculture Organization. Sustainable diets and biodiversity. Rome (Italy): Food; 2010.

5. Popkin BM. Relationship between shifts in food system dynamics and acceleration of the global nutrition transition. Nutr Rev. 2017;75:73-82. https://doi.org/10.1093/nutrit/nuw064

6. Imamura F, Micha R, Khatibzadeh S, Fahimi S, Shi P, Powles J, et al. Dietary quality among men and women in 187 countries in 1990 and 2010: a systematic assessment. Lancet Glob Health. 2015;3:e132-42. https://doi.org/10.1016/ s2214-109x(14)70381-x

7. Popkin B. Ultra-processed foods' impacts on health: $2030 \mathrm{food}$, agriculture and rural development in Latin America and the Caribbean. Santiago de Chile: Food and Agriculture Organization; 2020.

8. Johnston JL, Fanzo JC, Cogill B. Understanding sustainable diets: a descriptive analysis of the determinants and processes that influence diets and their impact on health, food security, and environmental sustainability. Adv Nutr. 2014;5:418-29. https://doi.org/10.3945/an.113.005553

9. Nogueira JP, Hatjiathanassiadou M, Souza SRG, Strasburg VJ, Rolim PM, Seabra LMJ. Sustainable perspective in public educational institutions restaurants: from foodstuffs purchase to meal offer. Sustainability (Switzerland). 2020;12:4340.

10. Cortese RDM, Martinelli SS, Fabri RK, Proença RPC, Cavalli SB. A label survey to identify ingredients potentially containing GM organisms to estimate intake exposure in Brazil. Public Health Nutr. 2018;21:2698-713. https://doi. org/10.1017/S1368980018001350

11. Auestad N, Fulgoni III, VL. What current literature tells us about sustainable diets: Emerging research linking dietary patterns, environmental sustainability, and economics. Adv Nutr. 2015;6:19-36. https://doi.org/10.3945/ an.114.005694

12. Meybeck A, Gitz V. Sustainable diets within sustainable food systems. Proc Nutr Soc. 2017;76:1-11. https://doi. org/10.1017/S0029665116000653

13. Menal-Puey S, Marques-Lopes I. Development of criteria for incorporating occasionally consumed foods into a national dietary guideline: a practical approach adapted to the spanish population. Nutrients. 2019;11(1):458. https://doi.org/10.3390/nu11010058

14. Swinburn BA, Kraak VI, Allender S, Atkins VJ, Baker PI, Bogard JR, et al. The global syndemic of obesity, undernutrition, and climate change. Lancet. 2019;393:791-846. https://doi.org/10.1016/S0140-6736(18)32822-8

15. Hawkes C, Popkin BM. Can the sustainable development goals reduce the burden of nutrition-related noncommunicable diseases without truly addressing major food system reforms? BMC Med. 2015;13:143. https://doi. org/10.1186/s12916-015-0383-7

16. Fardet A, Rock E. Perspective: reductionist nutrition research has meaning only within the framework of holistic and ethical thinking. Adv Nutr. 2018;9:655-70. https://doi.org/10.1093/advances/nmy044

17. Menezes MFG, Maldonado LA. Do nutricionismo à comida: a culinária como estratégia metodológica de educação alimentar e nutricional. Rev Hosp Univ Pedro Ernesto. 2015;14(3):82-90. https://doi.org/https://doi.org/10.12957/ rhupe.2015.19950

18. Scrinis G. On the ideology of nutritionism. London: Bloomsbury Academic; 2014.

19. O'Kane G. A moveable feast: contemporary relational food cultures emerging from local food networks. Appetite. 2016;105:218-31. https://doi.org/10.1016/j.appet.2016.05.010

20. Jennings HM, Thompson JL, Merrell J, Bogin B, Heinrich M. Food, home and health: the meanings of food amongst Bengali women in London. J Ethnobiol Ethnomed. 2014;10:44. https://doi.org/10.1186/1746-4269-10-44

21. Jacobs Jr DR, Tapsell LC. Food, not nutrients, is the fundamental unit in nutrition. Nutr Rev. 2007;65:439-50. https:// doi.org/10.1111/j.1753-4887.2007.tb00269.x 
22. Gil Á, Ruiz-López MD, Fernández-González M, Victoria EM. The finut healthy lifestyles guide: beyond the food pyramid. Nutr Hosp. 2015;31:2313-23. https://doi.org/10.3305/nh.2015.31.5.8803

23. Lawrence MA, Baker PI, Pulker CE, Pollard CM. Sustainable, resilient food systems for healthy diets: the transformation agenda. Public Health Nutr. 2019;22:2916-20. https://doi.org/10.1017/S1368980019003112

24. Sachs I. Desenvolvimento: includente, sustentável, sustentado. Rio de Janeiro: Garamond; 2004.

25. Food and Agriculture Organization. Food-based dietary guidelines. Rome: Organization; 2020 [cited 2020 Aug 2]. Available from: http://www.fao.org/nutrition/education/food-dietary-guidelines/background/en/

26. Martins KA, Freire MCM. Guias alimentares para populações: aspectos históricos e conceituais. Brasília Méd. 2008;45(4):291-302.

27. Freire MCM, Balbo PL, Amador MA, Sardinha LMV. Guias alimentares para a população brasileira: implicações para a Política Nacional de Saúde Bucal. Cad Saúde Pública. 2012;28(Suppl):s20-s9. https://doi.org/10.1590/S0102$311 \times 2012001300004$

28. Food and Agriculture Organization. Food-based dietary guidelines. Rome: Organization; 2020 [cited 2020 Sept 5]. Available from: http://www.fao.org/nutrition/education/food-dietary-guidelines/home/en/.

29. Food and Agriculture Organization. Plates, pyramids, planet: developments in national healthy and sustainable dietary guidelines: a state of play assessment. Rome: Organization; 2016.

30. Montagnese C, Santarpia L, Buonifacio M, Nardelli A, Caldara AR, Silvestri E, et al. European food-based dietary guidelines: a comparison and update. Nutrition. 2015;31:908-15. https://doi.org/10.1016/j.nut.2015.01.002

31. Herforth A, Arimond M, Álvarez-Sánchez C, Coates J, Christianson K, Muehlhoff E. A global review of food-based dietary guidelines. Adv Nutr. 2019;10:590-605. https://doi.org/10.1093/advances/nmy130

32. Rizk MT, Treat TA. Perceptions of food healthiness among free-living women. Appetite. 2015;95:390-8. https://doi. org/10.1016/j.appet.2015.08.003

33. Food and Agriculture Organization. Food-based dietary guidelines. Rome: Organization; 2017 [cited 2017 Mar 2]. Available from: http://www.fao.org/nutrition/education/food-based-dietary-guidelines/en/

34. Ferrari R. Writing narrative style literature reviews. Medical Writ. 2015;24:230-5. https://doi.org/10.1179/204748 0615Z.000000000329

35. Sobhani SR, Rezazadeh A, Omidvar N, Eini-Zinab H. Healthy diet: a step toward a sustainable diet by reducing water footprint. Sci Food Agr. 2019;99:3769-75. https://doi.org/10.1002/jsfa.9591

36. Willett W, Rockström J, Loken B, Springmann M, Lang T, Vermeulen S, et al. Food in the anthropocene: the EAT-Lancet Commission on healthy diets from sustainable food systems. Lancet. 2019;393:447-92. https://doi.org/10.1016/ s0140-6736(18)31788-4

37. World Health Organization. Healthy diet: fact sheet n³94 updated august 2018. Rome: Organization; 2018.

38. Paquette MC. Perceptions of healthy eating: state of knowledge and research gaps. Can J Public Health. 2005;96(Suppl3):S16-21. https://doi.org/10.1007/BF03405196

39. Ruanpeng D, Thongprayoon C, Cheungpasitporn W, Harindhanavudhi T. Sugar and artificially sweetened beverages linked to obesity: a systematic review and meta-analysis. QJM. 2017;110:513-20. https://doi.org/10.1093/qjmed/ hcx068

40. Scapin T, Fernandes AC, Proença RPC. Added sugars: definitions, classifications, metabolism and health implications. Rev Nutr. 2017;30:663-77. https://doi.org/10.1590/1678-98652017000500011

41. Belloir C, Neiers F, Briand L. Sweeteners and sweetness enhancers. Curr Opin Clin Nutr Metab Care. 2017;20:279-85. https://doi.org/10.1097/mco.0000000000000377

42. Proença RPC, Sousa AA, Veiros MB, Hering B. Qualidade nutricional e sensorial na produção de refeições. Santa Catarina: Universidade Federal de Santa Catarina; 2005.

43. Menegassi B. Eat regularly and carefully, in appropriate environments and in company: a brief analysis of this recommendation of the Brazilian Food Guide. Appetite. 2020;149:104619. https://doi.org/https://doi.org/10.1016/j. appet.2020.104619

44. Fabri RK, Proença RPC, Martinelli SS, Cavalli SB. Regional foods in Brazilian school meals. Br Food J. 2015;117:1706-19. https://doi.org/10.1108/BFJ-07-2014-0275

45. Ministério da Saúde (Brasil). Guia alimentar para a população brasileira: promovendo a alimentação saudável. Brasília: Ministério; 2006. 
46. Montanari M. Food is culture. New York: Columbia University Press; 2006.

47. Brillat-Savarin J-A. A fisiologia do gosto. São Paulo: Cia das Letras; 1995.

48. Rose D, Heller MC, Roberto CA. Position of the society for nutrition education and behavior: the importance of including environmental sustainability in dietary guidance. J Nutr Educ Behav. 2019;51:3-15.e1. https://doi. org/10.1016/j.jneb.2018.07.006

49. Hunter D, Borelli T, Beltrame DMO, Oliveira CNS, Coradin L, Wasike VW, et al. The potential of neglected and underutilized species for improving diets and nutrition. Planta. 2019;250:709-29. https://doi.org/10.1007/s00425019-03169-4

50. Leal ML, Alves RP, Hanazaki N. Knowledge, use, and disuse of unconventional food plants. J Ethnobiol Ethnomed. 2018;14:6. https://doi.org/10.1186/s13002-018-0209-8

51. Frison $E$, Clément $C$. The potential of diversified agroecological systems to deliver healthy outcomes: making the link between agriculture, food systems \& health. Food Policy. 2020:101851. https://doi.org/https://doi.org/10.1016/j. foodpol.2020.101851

52. United Nations. Transforming our world: the 2030 Agenda for Sustainable Development: General Assembley 70 session. New York: Department of Economic and Social Affairs; 2015.

53. Food and Agriculture Organization. Agroecology knowledge hub: overview. Rome: Organization; 2020 [cited 2020 May 22]. Available from: http://www.fao.org/agroecology/overview/en/

54. Cortese RDM, Martinelli SS, Fabri RK, Cavalli SB. Alimentação na atualidade: reflexões sobre o consumo de alimentos geneticamente modificados. Agroecología. 2018;12(2):71-9.

55. Almeida VES, Friedrich K, Tygel AF, Melgarejo L, Carneiro FF. Use of genetically modified crops and pesticides in Brazil: growing hazards. Ciênc Saúde Coletiva. 2017;22:3333-9.

56. Food Agriculture Organization. HLPE: agroecological and other innovative approaches for sustainable agriculture and food systems that enhance food security and nutrition. Rome: Organization; 2019. p.161. A report by the High Level Panel of Experts on Food Security and Nutrition of the Committee on World Food Security.

57. Béné C, Oosterveer P, Lamotte L, Brouwer ID, Haan S, Prager SD, et al. When food systems meet sustainability: current narratives and implications for actions. World Dev. 2019;113:116-30. https://doi.org/10.1016/j. worlddev.2018.08.011

58. Maluf RS, Burlandy L, Santarelli M, Schottz V, Speranza JS. Nutrition-sensitive agriculture and the promotion of food and nutrition sovereignty and security in Brazil. Ciêc Saúde Coletiva. 2015;20:2303-12. https://doi.org/10.1590/141381232015208.14032014

59. Von Koerber K, Bader N, Leitzmann C. Wholesome nutrition: an example for a sustainable diet. Proc Nutr Soc. 2017;76:34-41. https://doi.org/10.1017/S0029665116000616

60. Altieri MA, Nicholls $\mathrm{Cl}$, Henao A, Lana MA. Agroecology and the design of climate change-resilient farming systems. Agron Sustain Dev. 2015;35:869-90. https://doi.org/10.1007/s13593-015-0285-2

61. Brunori G, Galli F, Barjolle D, Van Broekhuizen R, Colombo L, Giampietro M, et al. Are local food chains more sustainable than global food chains? Considerations for assessment. Sustainability. 2016;8:1-27. https://doi. org/10.3390/su8050449

62. Shukla PR, Skea J, Calvo Buendia E, Masson-Delmotte V, Pörtner H-O, Roberts DC, et al. IPCC: Climate Change and Land: an IPCC special report on climate change, desertification, land degradation, sustainable land management, food security, and greenhouse gas fluxes in terrestrial ecosystems. Geneva: Intergovernmental Panel on Climate Change; @2019.

63. Hsieh H-F, Shannon SE. Three approaches to qualitative content analysis. Qual Health Res. 2005;15:1277-88. https:// doi.org/10.1177/1049732305276687

64. QSR International. NVivo: version 11. Melbourne: QSR International; 2015 [cited 2020. Aug 5]. Available from: https://www.qsrinternational.com/nvivo-qualitative-data-analysis-software/home

65. Buckton $\mathrm{CH}$, Lean ME, Combet E. Language is the source of misunderstandings: impact of terminology on public perceptions of health promotion messages. BMC Public Health. 2015;15:579. https://doi.org/10.1186/s12889-0151884-1

66. King JC. An evidence-based approach for establishing dietary guidelines. J Nutr. 2007;137:480-3. https://doi. org/10.1093/jn/137.2.480 
67. Bosi MLM. A nutriçäo na concepçäo científica moderna: em busca de um novo paradigma. Rev Nutr. 1994:32-47.

68. Bisogni CA, Jastran M, Seligson M, Thompson A. How people interpret healthy eating: contributions of qualitative research. J Nutr Educ Behav. 2012;44:282-301. https://doi.org/https://doi.org/10.1016/j.jneb.2011.11.009

69. Perignon M, Masset G, Ferrari G, Barré T, Vieux F, Maillot M, et al. How low can dietary greenhouse gas emissions be reduced without impairing nutritional adequacy, affordability and acceptability of the diet? A modelling study to guide sustainable food choices. Public Health Nutr. 2016;19:2662-74. https://doi.org/10.1017/ s1368980016000653

70. Girardi MW, Fabri RK, Bianchini VU, Martinelli SS, Cavalli SB. Oferta de preparações culinárias e alimentos regionais e da sociobiodiversidade na alimentação escolar: um estudo na Região Sul do Brasil. Segur Alim Nutr. 2018;25. https:// doi.org/10.20396/san.v25i3.8652261

71. Food and Agriculture Organization. Family farming and sustainable development at the CPLP. Portugal: Organizaton; 2019.

72. Aschemann-Witzel J. Consumer perception and trends about health and sustainability: trade-offs and synergies of two pivotal issues. Curr Opin Food Sci. 2015;3:6-10. https://doi.org/https://doi.org/10.1016/j.cofs.2014.08.002

73. Brink E, Van Rossum C, Postma-Smeets A, Stafleu A, Wolvers D, Van Dooren C, et al. Development of healthy and sustainable food-based dietary guidelines for the Netherlands. Public Health Nutr. 2019;22:2419-35. https://doi. org/10.1017/S1368980019001435

74. Feil AA, Cyrne CCS, Sindelar FCW, Barden JE, Dalmoro M. Profiles of sustainable food consumption: Consumer behavior toward organic food in southern region of Brazil. J Clean Prod. 2020;258:120690. https://doi.org/https:// doi.org/10.1016/j.jclepro.2020.120690

75. Verbeke W, Guerrero L, Almli VL, Vanhonacker F, Hersleth M. European consumers' definition and perception of traditional foods. In: Kristbergsson K, Oliveira J, editors. Traditional foods: general and consumer aspects. Boston: Springer; 2016.

76. Oliveira MSS, Santos LA. Guias alimentares para a população brasileira: uma análise a partir das dimensões culturais e sociais da alimentação. Ciênc Saúde Coletiva. 2018.

77. Ministério da Saúde (Brasil). Guia Alimentar para a população brasileira. 2a. ed. Brasília: Ministério; 2014.

78. Martinelli SS, Cavalli SB. Alimentação saudável e sustentável: uma revisão narrativa sobre desafios e perspectivas. Ciênc Saúde Coletiva. 2019;24:4251-62. 